A C G publications

Rec. Nat. Prod. 14:2 (2020) 129-138

records of natural products

\title{
Secondary Metabolites of Ethanol Extracts of Pinus sylvestris Cones from Eastern Anatolia and Their Antioxidant, Cholinesterase and $\alpha$-Glucosidase Activities
}

\author{
Meryem Topal ${ }^{*}$ \\ Gumushane University, Vocational School of Health Services, 29100-Gumushane, Türkiye \\ (Received June 01, 2019; Revised October 24, 2019; Accepted November 01, 2019)
}

\begin{abstract}
Scots pine (Pinus sylvestris) is the most widely distributed tree species among pine species. Antiradical, antioxidant properties and inhibition properties on butyrylcholinesterase (BChE), acetylcholinesterase (AChE) and $\alpha$-glycosidase activities of ethanol extracts of $P$. sylvestris were reported from Sarikamis (Kars), Gumushane and Erzurum provinces of Turkey. The cones of $P$. Sylvestris from Gumushane showed the highest $\mathrm{IC}_{50}$ values in both DPPH $(14.75 \mu \mathrm{g} / \mathrm{mL})$ and ABTS $^{+}(12.56 \mu \mathrm{g} / \mathrm{mL})$ radical scavenging activities. An LC-HRMS method developed and the secondary metabolite composition of extracts were identified. The major compounds are determined as (+)-trans taxifolin, quercitrin, fumaric acid, (-) epicatechin, and nepetin-7-O-glucoside, apigenin-7O-glucoside in P. sylvestris cones.
\end{abstract}

Keywords: Pinus sylvestris, acetylcholinesterase; butyrylcholinesterase; antioxidant activity; $\alpha$-glucosidase; LCHRMS. (C) 2019 ACG Publications. All rights reserved.

\section{Introduction}

Oxidation is a chemical reaction that separates electrons from an atom or molecule. If an atom loses its electron, it becomes oxidized. It represents an important part of our metabolism and aerobic life. Because of oxygen is used for energy producing in the form of ATP as the final electron acceptor in the electron transport system. A glitch in the transmission of these electrons causes serious problems [1]. Free radicals are extremely unsteady molecules. Molecules, atoms, or groups of atoms that can independently sustain their existence, containing one or more unpaired electrons, are called free radicals [2]. They react rapidly with other molecules to share these electrons. Free radicals are molecules that attack somatic cells and the immune system. Free radicals form the basis for electron transfer, energy production and other metabolic functions [3]. However, radicals become reactive because of the reduction of an electron in molecules entering the reaction, and this reaction causes uncontrolled behavior while continuing to chain, causing damage to the cell [4].

Active species derived from oxygen, including free radicals, play a role in tissue damage following ischemia and reperfusion of the heart and brain. Reactive oxygen species (ROS) occurs continuously during normal physiological events [1]. There is a continuous radical production due to various physical and chemical events in the environment. Too many and various radicals are produced in cellular conditions [3].

Antioxidant defense systems have been developed under normal physiological conditions to prevent the formation and release of free oxygen radicals and to remove them [4]. One of the most important requirements in quality life is healthy nutrition. Malnutrition causes many pathological and

* Corresponding author: E-Mail: topalmeryem@ hotmail.com 
physiological causes in the body. Healthy nutrition is very important to protect from diseases. Besides physical activity, abstaining from alcohol consumption and smoking are important tips for healthy and quality living. Antioxidant nutrition is especially important to get rid of the effects of free radicals [5].

Acetylcholinesterase (AChE, E.C.3.1.1.7), which is involved in nerve transmission by hydrolyzing acetylcholine, is an enzyme in the family of cholinesterases. Acetylcholinesterase, which is responsible for hydrolyzing choline esters, has been determined in high concentration in brain, nerve, and red blood cells. The decline in AChE activity causes nervous system disorders and even death [6]. Acetylcholine (ACh) is an important substrate for the enzyme acetylcholinesterase [7]. The sudden drop in acetylcholine level is fatal. Gradual decline in this level leads to Alzheimer's disease (AD) [6]. The human brain contains approximately 100 billion neurons. AD is a neurodegenerative disease caused by damage or death of these cells [8]. Butyrylcholinesterase (BChE) is commonly found in tissues such as the lung, brain, heart, liver, muscle, kidney, and body fluids such as serum, sweat, and cerebrospinal fluid. BChE is an important enzyme in the origin of the liver. It is produced in the liver and can hydrolyze or activate a large number of different compounds. $\mathrm{BChE}$ has been used as a marker of liver function in clinical trials. AD is a neurodegenerative disorder with symptoms such as impaired cognitive abilities, reduced memory, and personality changes [9].

The association of $\mathrm{AD}$ with acetylcholine is well known. To ensure that $\mathrm{ACh}$ remains in the synaptic range is one of the methods used in the treatment of AD. For this purpose, cholinesterase enzyme inhibitors are used [10]. BChE is structurally similar to AChE. On the other hand, unlike AChE, it has various physiological tasks. Since BChE is found in serum and is expressed in the liver, the level of inflammation in the tissues, especially serum, varies in many pathological conditions such as the presence of inflammation, nutritional status, tumor and neurophysiological disorders [11]. Diabetes mellitus (DM) is one of the most important health problems. It is caused by insufficiency, lack or ineffectiveness of insulin hormone produced from beta cells of pancreas. When diabetes mellitus occurs, glucose molecules cannot be metabolized. Consequently, glucose increases in the body, and insulin hormone cannot be secreted regularly against increased glucose. $\alpha$-Glucosidase enzyme is found on the brush surface of the small intestine. It is responsible for breaking down complex carbohydrates. The inhibitors of this enzyme help prevent hyperglycemia indirectly [6].

In pine forests, scots pine species are more common than other species. In Turkey, Northern Anatolia, East Anatolia, including Western Anatolia and Central Anatolia were examined under four different groups. Species grow predominantly in poorer, sandy soils, rocky tops, peat bogs, or near forest borders [12]. Scots Pine is a tree with a slender, cylindrical body with pointed hills and thin branches or fuller hulled, slender and thick branches, depending on the place of growth. Scots pine develops a narrowing hill by forming branches shortening towards the tip in early ages. The aged bodies of Scotch pine are gray-brown, thick and cracked. Scots pine needs little heat and water. It can grow in many different climates because it is frost resistant. Therefore, it can grow both at sea level and in high altitude regions. It is usually spread in mountainous regions but also in high ovals and narrow valley bases. Scots Pine is the tree of light sandy soil [13]. Scots pine grows in soils with low mineral content, and less moisture. Scots Pine wood contains $41.9 \%$ cellulose, $12.8 \%$ hexose, $8.7 \%$ pentosane, $29.5 \%$ lignin, $3.2 \%$ fat and $1.3 \%$ ash [27]. Scots Pine wood has a matte color. The resin is fragrant when it is green. It has a decorative appearance. This wood is as hard as possible and medium weight $[14,15]$. Recently, the examination of the content of natural products has increased and this has opened the way for alternative medicine. Some parts of pine species including bark, needles, resin and cones are used as anti-inflammatory, antioxidant or antiseptic. For the reproduction of conifers, the presence and number of cones is also very important. As they protect and mature the seeds during development, the oaks opens and the seeds spread over a wide area [16]. It was well known that scots pine species had a common usage in folk medicine. The paste obtained by crushing scots pine seeds with honey is used as a strengthener. The scots pine seeds are pressed in the industry to obtain light yellow, odorless and delicious oil in Anatolian kitchen and confectionery. This oil is also used in the manufacture of soap, cosmetics and varnish [17]. Also, it was reported that some product obtained from Scots pine had tropical counter irritants fort the treatment of rheumatic disorders and muscle pain and as anti-aging cosmetics [18].

Foods of plant origin provide not only important antioxidant vitamins to life metabolism, but also natural compounds with antioxidant effect [11]. Recent studies have shown that compounds with antioxidant activity are highly effective in preventing many degenerative diseases such as cancer, 
cardiovascular diseases, neurological diseases, and cataracts, caused by oxidative stress [19]. The antioxidant properties, and inhibition effects on $\mathrm{AChE}, \mathrm{BChE}$ and $\alpha$-glucosidase enzymes of $P$. sylvestris cones collected from Sarikamis (Kars), Gumushane, and Erzurum regions were examined in this study. The results obtained will be effective and guiding for food, cosmetic, alternative medicine, and pharmaceutical sectors. The inhibition of $\mathrm{AChE}, \mathrm{BChE}$ and $\alpha$-glucosidase enzymes and high antioxidant capacity will prevent these cones from health problems such as diabetes, $\mathrm{AD}$, asthma, cancer, organophosphate intoxication, cocaine poisoning, rheumatoid arthritis, anesthetic apnea, cardiovascular diseases and small cell lung cancer. Phenolic contents of $P$. sylvestris shells have been studied in the literature using different methods [20]. Antioxidant activities, phenolic contents and enzyme inhibition of cones of this species were not studied. Hence, P. sylvestris cones, which are a natural product, have been studied and presented to the scientific community.

The main goal of this study is to determine the antioxidant activity of ethanol extracts of Scots pine (Pinus sylvestris) cones collected from different parts of Eastern Anatolia using by distinct bioanalytical methods including the cupric $\left(\mathrm{Cu}^{2+}\right)$ and ferric $\left(\mathrm{Fe}^{3+}\right)$ ions reducing abilities, $\mathrm{ABTS}^{\cdot+}$ and $\mathrm{DPPH}^{\cdot}$ scavenging activities. And to demonstrate the inhibitory abilities of the extract against the acetylcholinesterase, butyrylcholinesterase and $\alpha$-glucosidase enzymes, which are linked to global and common health diseases and the secondary metabolite profile of extract of species were determined and structure activity relationship evaluated herein.

\section{Materials and Methods}

\subsection{Plant Material and Extraction}

P. sylvestris cones were collected in June from Erzurum, Sarikamis (Kars) and Gumushane provinces of Turkey. A voucher specimen of Gumushane (ATA 9878), Erzurum (ATA 9879) and Sarikamis (ATA 9880) P. sylvestris cones has been deposited at Atatürk University Faculty of Science Herbarium. $100 \mathrm{~g}$ of dried cones of each sample shredded with a blender and $150 \mathrm{~mL}$ of ethyl alcohol were added and macerated 24 hours. Then the mixture was filtered through filter paper and the remaining pulp was further extracted with $100 \mathrm{~mL}$ ethyl alcohol under the same conditions and filtered again. Then the extracts were combined, and ethanol was removed in the rotary evaporator at $35^{\circ} \mathrm{C}$ under vacuum. The extracts were placed in plastic bottles, and then stored at $-20^{\circ} \mathrm{C}$ until further experiments.

\subsection{Antioxidant Capacity Assays}

$\mathrm{Fe}^{3+}$ reduction capacity and $\mathrm{Cu}^{2+}$ reduction capacity (Cuprac method) assays were performed according to the method of Oyaizu et al. [21] and Apak et al., respectively [22]. DPPH free radical scavenging activity was performed according to Blois method as described in previous studies [23] and ABTS radical scavenging activity was determined according to the method of Re et al. [24]. Detailed informations of applied methods are given in supporting information.

\subsection{Determination of Total Phenolic and Flavonoid Contents}

Total phenolic contents in P. sylvestris cones were determined by using Folin-Ciocalteu regent [2] and The total flavonoid content of cone extracts was determined by using the method of literature and quercetin used as a standard in this method [9]. Detailed information of applied methods are given in supporting information.

\subsection{Enzyme Activity Assays}

$\mathrm{AChE}$, and BChE inhibition activities were carried out according to the Ellman's method [25] and $\alpha$-glucosidase enzyme (E.C.3.2.1.20) inhibition patterns were determined via the well known procedure and $p$-NPG was used as a substrate [6]. Detailed information of applied methods are given in supporting information. 


\subsection{Statistical Analysis}

Each experiment was performed three times. The obtained data were recorded as mean \pm standard deviation and analyzed with SPSS (Windows 2000, version 11.5 for SPSS Inc., Chicago, IL). Variance ANOVA including one-way analysis was realized. Significant differences between the averages were determined by Duncan's Multiple Range tests.

\subsection{Chromatography conditions}

Liquid Chromatography High Resolution Mass Spectrometry (LC-HRMS) measurements were performed with a Thermo Orbitrap Q-Exactive instrument in ESI Source and equipped with a Fortis C18 column (150 $\mathrm{mm} \times 2.1,3 \mu \mathrm{m}$ particle size). The mobile phase was composed of water (A, $0.1 \%$ formic acid) and methanol (B, $0.1 \%$ formic acid), the gradient programme of which was $0-1.00 \mathrm{~min}$ $40 \% \mathrm{~A}$ and $60 \% \mathrm{~B}, 1.01-05.00 \mathrm{~min} 100 \% \mathrm{~B}$ and finally $60-10 \mathrm{~min} 40 \% \mathrm{~A}$ and $60 \% \mathrm{~B}$. The flow rate of the mobile phase was $0.30 \mathrm{~mL} / \mathrm{min}$, and the column temperature was set to $22^{\circ} \mathrm{C}$. The injection volume was $2 \mu \mathrm{L}$. The best mobile phase solution was determined to be a gradient of acidified methanol and water system as reported above. Such a mobile phase was determined to be satisfactory for the ionization abundance and separation of the compounds. The good ionization of small and relatively polar antioxidants was obtained by the ESI source. The ions between $\mathrm{m} / \mathrm{z}$ 85-1200 were scanned in highresolution mode of instrument. Identification of compounds was done by comparison of retention time of standard compounds (in the range of purity 95\% - 99\%) and HRMS data of Bezmialem Vakif University, Drug Application and Research Center Library (ILMER). Freshly prepared curcumin (purity $97 \%)$ used as an internal standard.

The working solutions are prepared as follow. $168.5 \mathrm{mg}$ (Erzurum), $234.2 \mathrm{mg}$ (Sarikamis) and $120.9 \mathrm{mg}$ (Gumushane) of methanol extracts of $P$. sylvestris weighed and dissolved in $5 \mathrm{~mL}$ of with a $2.5 \mathrm{~mL}$ of mobile phase (Mobil Phase A: B; 50:50). Then, from $100 \mathrm{mg} / \mathrm{L}$ internal standard solution is added to the final concentration of $3 \mathrm{ppm}$ and volume was completed to $5 \mathrm{~mL}$ with mobile phase. Then, the solution was filtered through a $0.45 \mu$ filter and $2 \mu \mathrm{L}$ was added to the instrument [26].

\section{Results and Discussion}

P. sylvestris is a species of the genus Pinus of the Pinaceae family from the Gymnospermae class. $P$. sylvestris has the widest geographic distribution of species present in the pine species. $P$. sylvestris constitutes $5.5 \%$ of the total forest area in Turkey. In the area covered by coniferous plants in Turkey, $P$. sylvestris ranks $3^{\text {rd }}$ after $P$. nigra and $P$. brutia [27]. It is aimed to produce male and female flowers, which are the main objective in seed gardens. Accordingly, seeds produced with cone and seed yield should be of good quality. It is very important to determine differences between cones [28]. The cones may differ in their different populations. Seed retention depends largely on the genetic characteristics of the tree species and climate variability. Light seeded trees hold usually seeds earlier than their heavy seeds. Light trees also hold seeds at earlier ages than shade trees. P. sylvestris indicates that the seed rate is low and sparse at high altitudes [29]. Forest trees begin to hold cones at certain ages. Retention of cones varies depending on the type of aging, genetic structure, characteristics of the growing environment and climate factors. Pile of cones and cones holds abundantly in poor and unfavorable soils for fear of termination of trees [30].

\subsection{Determination of Secondary Metabolites}

It has been determined that the phenolic components of the secondary metabolites are identified as anti-inflammatory, antitumor, antiviral, antiallergic, antimicrobial, antimutagenic, antioxidant, and anticancer agent [26]. Phenolic compounds effectively prevent oxidation in nutrient systems and serve as a protective factor against oxidative damage in the human body [9].

Thus, it is very important to understand the mechanisms of action of phenolic and flavonoid substances which have important effects on human health and to investigate the ways in which they can 
be used [1]. Total phenolics and total flavonoid contents of the ethanol extracts of Sarkamis, Gumushane and Erzurum $P$. sylvestris cones were determined herein (Table 1).

Table 1. Total flavonoids content as quercetin equivalent (QE/mg of extract) and total phenolic content as gallic acid equivalent (GAE/mg of extract) in $P$. sylvestris cones

\begin{tabular}{lcc}
\hline Antioxidants & Total Phenolic $(\boldsymbol{\mu g}$ GAE $/ \mathbf{m g})$ & Total Flavonoid $(\boldsymbol{\mu g} \mathbf{Q E} / \mathbf{m g})$ \\
\hline Sarikamis & 99.09 & 10.22 \\
Erzurum & 123.64 & 12.22 \\
Gumushane & 131.82 & 14.44 \\
\hline
\end{tabular}

In addition to those data, determination of phenolic acid contents of $P$. sylvestris cones were analyzed by using LC-HRMS. Table 2 shows the information on the concentration of identified secondary metabolites in ethanol extracts and the sample chromatograms are given for ethanol extract of $P$. sylvestris in Figure 1.

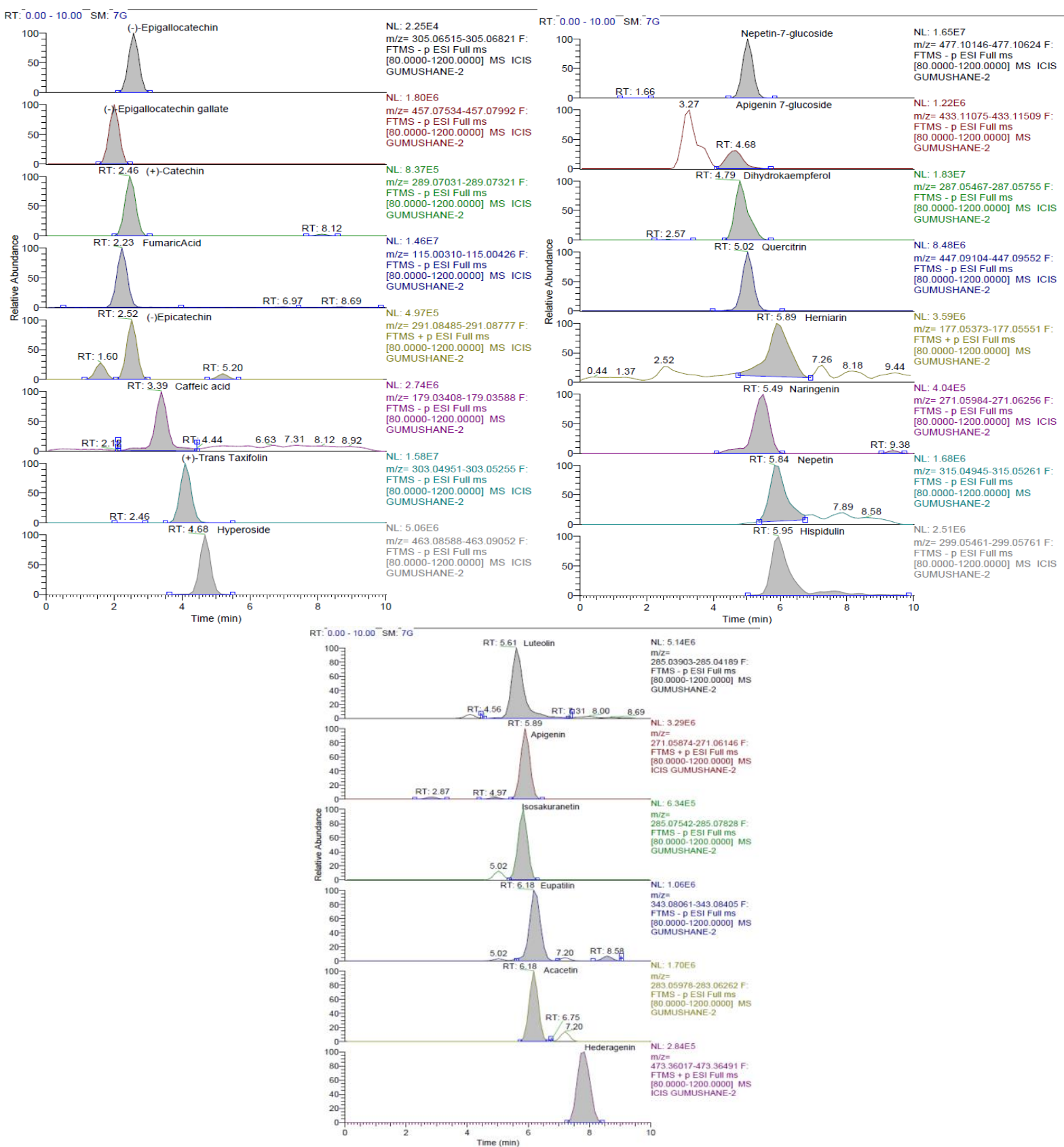

Figure 1. LC-HRMS chromatogram of ethanol extract of $P$. sylvestris cone (Gumushane) 
The mass parameters and linear regression equations of were reported for the compounds by LCHRMS (See Table S1). Measurement uncertainty values are given together with the results in Table 1 $\% \mathrm{U}(\mathrm{k}=2,95 \%$ confidence interval). Measurement uncertainty is determined in accordance with GUM and EA-4/02 documents.

The results showed that the ethanol extract of Gumushane P. sylvestris cone $(131.82 \mu \mathrm{g}$ $\mathrm{GAE} / \mathrm{mg}$ ) contained more total phenolic compounds and flavonoids (14.44 $\mu \mathrm{g} \mathrm{QE} / \mathrm{mg})$ than the others (Table 2). Those data shows the strong correlation of antioxidant capacity and phenolics contents of the extracts as described before [26]. In order to identify the phenolic contents of the extracts, secondary metabolite composition of them were analyzed by LC-HRMS (see Table S1 and Table 3).

Table 2. Compounds determined in P. sylvestris cone extracts and their amounts (g extract)

\begin{tabular}{|c|c|c|c|c|}
\hline Compounds & Erzurum & Sarikamis & Gumushane & $\mathrm{U} \%(\mathrm{k}=2)$ \\
\hline (-) Epigallocatechin & 0.01 & 0.01 & 0.03 & 3.11 \\
\hline (-) Epigallocatechin gallate & 0.11 & 0.05 & 0.45 & 2.73 \\
\hline (+) Catechin & 0.62 & 0.50 & 0.05 & 1.84 \\
\hline Fumaric Acid & 2.25 & 1.13 & 5.51 & 3.15 \\
\hline (-) Epicatechin & 1.32 & 1.12 & 0.08 & 3.62 \\
\hline Verbascoside & 0.01 & $<\mathrm{LOD}$ & $<\mathrm{LOD}$ & 3.59 \\
\hline Caffeic acid & 0.19 & 0.76 & 0.13 & 2.41 \\
\hline Luteolin-7-rutinoside & 0.01 & $<\mathrm{LOD}$ & $<\mathrm{LOD}$ & 1.43 \\
\hline Hesperidin & $<\mathrm{LOD}$ & 0.02 & $<\mathrm{LOD}$ & 2.82 \\
\hline (+) trans Taxifolin & 2.61 & 1.01 & 1.12 & 2.97 \\
\hline Hyperoside & 3.08 & 0.48 & 1.75 & 3.01 \\
\hline Rosmarinic acid & $<\mathrm{LOD}$ & $<\mathrm{LOD}$ & $<\mathrm{LOD}$ & 4.38 \\
\hline Nepetin-7-O-glucoside & 1.56 & 0.56 & 1.64 & 4.39 \\
\hline Apigenin 7-O-glucoside & $<\mathrm{LOD}$ & 0.26 & 0.33 & 3.13 \\
\hline Dihydrokaempferol & 0.28 & 0.22 & 1.06 & 3.80 \\
\hline Quercitrin & 0.61 & 0.29 & 0.61 & 4.78 \\
\hline Myricetin & 0.02 & 0.01 & $<\mathrm{LOD}$ & 1.71 \\
\hline Herniarin & 0.01 & $<\mathrm{LOD}$ & 0.01 & 0.94 \\
\hline Naringenin & 0.02 & 0.04 & 0.04 & 4.15 \\
\hline Nepetin & 0.01 & $<\mathrm{LOD}$ & 0.02 & 3.21 \\
\hline Rhamnocitrin & $<\mathrm{LOD}$ & 0.01 & $<\mathrm{LOD}$ & 2.76 \\
\hline Hispidulin & 0.19 & 0.06 & 0.40 & 1.73 \\
\hline Kaempferol & 0.03 & 0.02 & $<\mathrm{LOD}$ & 0.91 \\
\hline Luteolin & 0.01 & 0.01 & 0.03 & 1.91 \\
\hline Apigenin & 0.02 & 0.04 & 0.04 & 2.72 \\
\hline Isosakuranetin & 0.26 & 0.09 & 0.20 & 1.21 \\
\hline Eupatilin & 0.16 & 0.08 & 0.31 & 1.38 \\
\hline Chrysin & 0.01 & $<\mathrm{LOD}$ & $<\mathrm{LOD}$ & 1.19 \\
\hline Acacetin & 0.10 & 0.02 & 0.08 & 1.50 \\
\hline Quillaic acid & 0.09 & 0.05 & $<\mathrm{LOD}$ & 3.01 \\
\hline Hederagenin & 0.17 & $<\mathrm{LOD}$ & 0.41 & 9.23 \\
\hline
\end{tabular}


The major compounds are determined as hyperoside, trans taxifolin, nepetin-7-o-glucoside, apigenin 7-O-glucoside, dihydrokaemferol, hispudilin, eupatulin and hederaganin. In addition to those the highest content of fumaric acid determined in that extract. Thus we clearly conclude that the strong antioxidant capacity of extract of $P$. sylvestris from Gumushane comes from those secondary metabolites (Table 2).

\subsection{Antioxidant Capacity}

The reduction capacity of a compound can be measured by different methods. One of the most commonly used methods for this purpose can be measured by reducing $\left[\mathrm{Fe}(\mathrm{CN}]_{6}\right]^{3+}$ to $\left[\mathrm{Fe}(\mathrm{CN})_{6}\right]^{2+}[27]$. Comparing the reduction forces of ferric ions $\left(\mathrm{Fe}^{3+}\right)$ of the standard antioxidants and the P. sylvestris cones at $20 \mu \mathrm{g} / \mathrm{mL}$ concentration: BHA $\left(\mathrm{r}^{2}: 0.9539\right)>$ Trolox $\left(\mathrm{r}^{2}: 0.9138\right)>\alpha$-Tocopherol $\left(\mathrm{r}^{2}: 0.9938\right)>$ BHT $\left(r^{2}: 0.9685\right)>$ Gumushane $\left(r^{2}: 0.9912\right)>$ Erzurum $\left(r^{2}: 0.9909\right)>$ Sarikamis $\left(r^{2}: 0.9937\right)$. In the present study, the capacity to reduce the ferric ions $\left(\mathrm{Fe}^{3+}\right)$ to the ferrous ions $\left(\mathrm{Fe}^{2+}\right)$ as well as the reduction of cupric ions $\left(\mathrm{Cu}^{2+}\right)$ to the cuprous ions $\left(\mathrm{Cu}^{+}\right)$was also studied. Cuprac method has gained widespread use in recent years [31]. This method is a low cost, fast, stable and convenient method. The activity of reducing cupric ions $\left(\mathrm{Cu}^{2+}\right)$ of the $P$. sylvestris cones and standard antioxidants at $20 \mu \mathrm{g} / \mathrm{mL}$ concentration are compared with each other: BHA $\left(\mathrm{r}^{2}: 0.8886\right)>$ BHT $\left(\mathrm{r}^{2}: 0.9675\right)>$ Trolox $\left(\mathrm{r}^{2}: 0.9998\right)$ $>$ Gumushane $\left(r^{2}: 0.9999\right)>$ Erzurum $\left(r^{2}: 0.9806\right)>\alpha$-Tocopherol $\left(r^{2}: 0.9786\right)>$ Sarikamis $\left(r^{2}: 0.9760\right)$.

As shown above, antioxidant and antiradical studies were compared with standard antioxidants such as $\alpha$-Tocopherol, BHT, BHA, and Trolox. In most antioxidant models, $P$. sylvestris cones of equal concentrations and activities of standard antioxidants showed that Gumushane P. sylvestris cones had higher activity. Reduction capacity is one of the most important factors in the antioxidant activity of a compound. The reducing power of a compound is related to antioxidant activity [31].

The methods based on the use of $\mathrm{DPPH}$ and $\mathrm{ABTS}^{+}$radicals are the spectrophotometric methods commonly used to determine the antioxidant capacity of pure substances, food, beverages and vegetable extracts [8]. The DPPH radical is a stable long-life nitrogen-free radical. It is one of the most commonly used methods to determine the radical scavenging activity of antioxidants [19].

When the $\mathrm{IC}_{50}$ values of DPPH radical scavenging activity of $P$. sylvestris cones and the standard antioxidants were compared, it was observed that the Gumushane $P$. sylvestris cone $(14.75 \mu \mathrm{g} / \mathrm{mL})$ had a higher $\mathrm{IC}_{50}$ value than the other cones (Table 1$)$. Trolox $(7.62 \mu \mathrm{g} / \mathrm{mL})$ has a relatively high $\mathrm{IC}_{50}$ value. These values have been observed to be quite high when compared with some pure antioxidants isolated from purified vegetal sources. For example, DPPH radical scavenging activities of both alcohol and

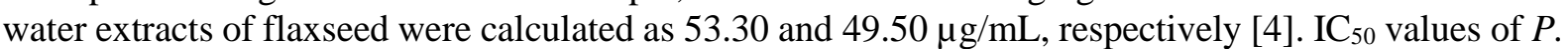
sylvestris cones were calculated between $14.75-30.13 \mu \mathrm{g} / \mathrm{mL}$ (Table 3). When the results were examined, it was observed that cones have higher antioxidant activity than curcumin $(34.9 \mu \mathrm{g} / \mathrm{mL})$ determined in the literature.

Table 3. $\mathrm{IC}_{50}(\mu \mathrm{g} / \mathrm{mL})$ values of $\mathrm{DPPH}^{\bullet}$ and $\mathrm{ABTS}^{\cdot+}$ radicals scavenging activities of $P$. sylvestris cones and standard antioxidants

\begin{tabular}{lcc}
\hline Antioxidants & DPPH· scavenging & ABTS $^{++}$scavenging \\
\hline Sarikamis & 30.13 & 14.63 \\
Erzurum & 21.00 & 12.82 \\
Gumushane & 14.75 & 12.56 \\
BHA & 9.90 & 11.73 \\
BHT & 12.38 & 11.77 \\
$\alpha$-Tocopherol & 12.38 & 12.11 \\
\hline
\end{tabular}

The radical scavenging activities of antioxidant compounds are very important in eliminating the damage caused by free radicals to the organism in the biological systems, food and pharmaceutical industry. In these systems, free radicals occur and accelerate lipid peroxidation, thus reducing the quality of products [32]. In the study, Table 2 shows that the $P$. sylvestris cones used have been able to scavenge ABTS radicals quite strongly. In the determination of ABTS radicals, $\mathrm{IC}_{50}$ values of ethanol extracts of $P$. sylvestris cones were found to be $12.56-14.63 \mu \mathrm{g} / \mathrm{mL}$. These values were found to be parallel to the standard antioxidants as shown in Table 3. 


\subsection{Acetylcholinesterase (AChE) and Butyrylcholinesterase (BChE) Activity}

Acetylcholinesterase (AChE) is an enzyme that hydrolyses the acetylcholine compound involved in the communication between synapses in the nervous system. It is usually a member of the family of carboxylesterase enzymes as found in the synapses of the muscle and brain nerves [36]. Butyrylcholinesterase (BChE) synthesizes in liver and releases into circulation. The classic role of $\mathrm{BChE}$ is the hydrolysis of succinylcholine, which is used as a local anesthetic. Succinylcholine is used as a short-term muscle relaxant prior to general anesthesia in surgery. $\mathrm{BChE}$ is the only enzyme that can break down succinylcholine in the organism [19]. The substrate selectivity of cholinesterases is different. AChE can rapidly hydrolyze a natural neurotransmitter, acetylcholine, compared to other large acyl-tailed choline esters, while BChE can rapidly hydrolyze synthetic substrates, mainly butyrylcholine [11].

When this disease is treated using by cholinesterase inhibitors, the acetylcholine becomes normal levels. Consequently, cognitive and behavioral disorders can be treated to a certain extent. In our study, the inhibition levels of cones, a natural product, on these two enzymes were determined. $\mathrm{IC}_{50}$ values are as given in Table 4. The calculated values were determined to be quite effective compared to natural products. Especially, the Gumushane P. sylvestris cone was found to be the most effective inhibition (AChE and $\mathrm{BChE}$ ) of cones. According to the results, it can be used in the treatment of AD.

Table 4. $\mathrm{IC}_{50}$ values of the enzyme inhibition results

\begin{tabular}{lccc}
\hline Region & AChE $(\mathbf{m g} / \mathbf{m L})$ & BChE $(\mathbf{m g} / \mathbf{m L})$ & $\boldsymbol{\alpha}$-Glucosidase $(\mathbf{m g} / \mathbf{m L})$ \\
\hline Sarikamis & 7.96 & 2.72 & 43.31 \\
Erzurum & 9.91 & 3.48 & 40.76 \\
Gumushane & 6.41 & 2.22 & 26.65 \\
Tacrin & 0.97 & 1.66 & - \\
Acarbose & - & - & 0.015 \\
\hline
\end{tabular}

\section{3. $\alpha$-Glucosidase Activity}

Oxidative stress is one of the important markers of Type-2 diabetes [19]. The antioxidant molecules used to minimize the effects of oxidative stress can also be used as an inhibitor of $\alpha$ glucosidase enzyme [6]. Inhibition effects of cones from different regions in Eastern Anatolia on $\alpha$ glucosidase enzyme were investigated and the results are showed in Table 3. Sarikamis and Erzurum $P$. sylvestris cones showed close inhibition while Gumushane P. sylvestris cone $(26.65 \mathrm{mg} / \mathrm{mL})$ showed more effective inhibition. IC $_{50}$ value of acarbose, which used as the $\alpha$-glucosidase inhibitor, was found to be $0.015 \mathrm{mg} / \mathrm{mL}$. It is thought that cones obtained from natural product will guide oral diabetic drug groups according to these values [32].

As a conclusion, $P$. sylvestris cones in 3 from different province of Turkey with different terrestrial climates were compared herein. Both enzyme inhibition values and antioxidant capacities of Gumushane P. sylvestris cone were found to be more effective than other cones. The reason is thought to be due to the fact that it's high phenolic content. A similar study is reported on the radical scavenging effects, total flavonoid and phenolic contents of $P$. sylvestris of water extracts of whole bark and outer bark grown in the coastal and continental regions of Kaliningrad region (Russia) were reported with a small amounts of tannin contents and flavonoid content are reported as 2.1-5.2 mg/g [33]. According to those results, I clearly state that the cone extracts of $P$. sylvestris may be a source of natural antioxidants and anticholinesterase products.

\section{Acknowledgments}

In this study, Herbarium numbers were determined by Prof. Yusuf Kaya, Ataturk University, Faculty of Science, Department of Biology, Erzurum, Turkey. 


\section{Supporting Information}

Supporting information accompanies this paper on http://www.acgpubs.org/journal/records-of$\underline{\text { natural-products }}$

\section{ORCID}

Meryem Topal: $\underline{0000-0002-2107-8603}$

\section{References}

[1] I. Gulcin (2012). Antioxidant activity of food constituents-an overview, Arch. Toxicol. 86, 345-391.

[2] M.H. Sehitoglu, H. Han, P. Kalin, I. Gulcin, A. Ozkan and H.Y. Aboul-Enein (2015). Pistachio (Pistacia vera L.) Gum: a potent inhibitor of reactive oxygen species, J. Enzyme Inhib. Med. Chem. 30, 264-269.

[3] B. Halfon, O. Cetin, G. Kokdil and G. Topcu (2019). Chemical investigation and bioactivity screening of Salvia cassia Extracts, Rec. Nat. Prod. 13(2), 156-166.

[4] H. Han, H. Y1lmaz and I. Gulcin (2018). Antioxidant activity of flaxseed (Linum usitatissimum L.) and analysis of its polyphenol contents by LC-MS/MS, Rec. Nat. Prod. 12(4), 397-402.

[5] K. Aksu, F. Topal, I. Gulcin, F. Tumer and S. Goksu (2015). Acetylcholinesterase inhibitory and antioxidant activities of novel symmetric sulfamides derived from phenethylamines, Arch. Pharm. 348(6), 446-455.

[6] E. Bursal, A. Aras, O. Kilic, P. Taslimi, A.C. Goren and I. Gulcin (2019). Phytochemical content, antioxidant activity and enzyme inhibition effect of Salvia eriophora Boiss. \& Kotschy against acetylcholinesterase, $\alpha$-amylase, butyrylcholinesterase and $\alpha$-glycosidase enzymes, J. Food Biochem. 43(3), e12776.

[7] H. Tohma, A. Altay, E. Koksal, A.C. Gören and I. Gulcin (2019). Measurement of anticancer, antidiabetic and anticholinergic properties of sumac (Rhus coriaria)-Analysis of its phenolic compounds by LCMS/MS, J. Food Measure. 13(2), 1607-1619.

[8] G. Maharramova, P. Taslimi, A. Sujayev, F. Farzaliyev, L. Durmaz and I. Gulcin (2018). Synthesis, characterization, antioxidant, antidiabetic, anticholinergic, and antiepileptic properties of novel Nsubstituted tetrahydropyrimidines based on phenylthiourea, J. Biochem. Mol. Toxicol. 32(12), e22221.

[9] H. Tohma, I. Gulcin, E. Bursal, A.C. Goren, S.H. Alwasel and E. Koksal (2017). Antioxidant activity and phenolic compounds of ginger (Zingiber officinale Rosc.) determined by HPLC-MS/MS, J. Food Measure. 11(2), 556-566.

[10] C.I. Wright, C. Geula and M.M. Mesulam (1993). Neurological cholinesterases in the normal brain and in Alzheimer's disease: relationship to plaques, tangles, and patterns of selective vulnerability, Ann Neurol. 34(3), 373-384.

[11] C. Bayrak, P. Taslimi, I. Gulcin and A. Menzek (2017). The first synthesis of 4-phenylbutenone derivative bromophenols including natural products and their inhibition profiles for carbonic anhydrase, acetylcholinesterase and butyrylcholinesterase enzymes, Bioorg. Chem. 72, 359-366.

[12] I. Turna (2003). Variation of some morphological and electrophoretic characters of 11 populations of scots pine in Turkey, Isr. J. Plant Sci. 51(3), 223-230.

[13] W.T. Sinclair, J.D. Morman and R.A. Ennos (1999). The postglacial history of Scots pine (P. sylvestris L.) in western Europe: evidence from mitochondrial DNA variation, Mol. Ecol. 8(1), 83-88.

[14] H. Ucuna, Y.K. Bayhan, Y. Kaya, A. Cakici and O.F. Algur (2002). Biosorption of chromium (VI) from aqueous solution by cone biomass of Pinus sylvestris, Bioresour. Technol. 85(2), 155-158.

[15] I.C. Anderson, C.D. Campbell and J.I. Prosser (2003). Diversity of fungi in organic soils under a moorland - Scots pine (P. sylvestris L.) gradient, Environ. Microbiol. 5(11), 1121-32.

[16] J.H. Bae, Y.J. Park, J. Namiesnik, I. Gulcin, T.C. Kim, H.C. Kim, B.G. Heo, S. Gorinstein and Y.G. Ku (2016). Effects of artificial lighting on bioactivity of sweet red pepper (Capsicum annuum L.), Int. J. Food Sci. Technol. 51(6), 1378-1385.

[17] https://www.yesilaski.com/cam-agaclarinin-tedavide-kullanilisi.html.24.10.2019.

[18] O. Ustun, F.S. Senol, M. Kurkcuoglu, I.E. Orhan, M. Kartal and K.H.C. Baser, (2012). Investigation on chemical composition, anticholinesterase and antioxidant activities of extracts and essential oils of Turkish Pinus species and pycnogenol, Ind. Crops Prod. 38, 115-123.

[19] P. Taslimi, C. Caglayan, F. Farzaliyev, O. Nabiyev, A. Sujayev, F. Turkan, R. Kaya and I. Gulcin (2018). Synthesis and discovery of potent carbonic anhydrase, acetylcholinesterase, butyrylcholinesterase and $\alpha$ - 
glycosidase enzymes inhibitors: the novel N,N'-bis-cyanomethylamine and alkoxymethylamine derivatives, J. Biochem. Mol. Toxicol. 32(4), e22042.

[20] M. Karonen, M. Hamalainen, R. Nieminen, K.D. Klika, J. Loponen, V.V. Ovcharenko, E. Moilanen and K. Pihlaja (2004). Phenolic extractives from the Bark of $P$. sylvestris L. and their effects on inflammatory mediators nitric oxide and prostaglandin $\mathrm{E}_{2}$, J. Agric. Food Chem. 52(25), 7532-7540.

[21] M. Oyaizu (1986). Studies on products of browning reaction prepared from glucoseamine, Jpn. J. Nutr. Diet. 44, 307-314.

[22] R. Apak, K. Guclu, M. Ozyurek, S.E. Karademir and E. Ercal (2006). The cupric ion reducing antioxidant capacity and polyphenolic content of some herbal teas, Int. J. Food Sci. Nutr. 57, 292-304.

[23] M.S. Blois (1958). Antioxidant deteminations by the use of a stable free radical, Nature 26, 1199-1200.

[24] R. Re, N. Pellegrini, A. Proteggente, A. Pannala, M. Yang and C. Rice-Evans (1999). Antioxidant activity applying an improved ABTS radical cation decolorization assay, Free Rad. Biol. Med. 26, 1231-1237.

[25] G.L. Ellman, K.D. Courtney, V. Andres and R.M. Featherston (1961). A new and rapid colorimetric determination of acetylcholinesterase activity, Biochem. Pharmacol. 7, 88-90.

[26] I. Gulcin, E. Bursal, M. H. Şehitoğlu, M. Bilsel and A.C. Gören (2010). Polyphenol contents and antioxidant activity of lyophilized aqueous extract of propolis from Erzurum, Turkey, Food Chem. Toxicol. 48(8-9), 2227-2238.

[27] K.S. Kang and D. Lindgren (1998). Fertility variation and its effect on the relatedness of seeds in Pinus densiflora, Pinus thunbergii and Pinus koraiensis clonal seed orchards, Silvae Genet. 47, 196-201.

[28] F. Prescher (2007). Seed orchards-genetic considerations on function, management and seed procurement. Acta Universitatis Agriculturae, Doctoral Thesis, XI Chapters and p 49. Umea.

[29] N. Bilir, F. Prescher, D. Lindgren and J. Kron (2008). Variation in seed related characters in clonal seed orchards of Pinus sylvestris, New Forest. 36, 187-199.

[30] V.C. Taty-Costodes, H. Fauduet, C. Porte and A. Delacroix (2003). Scavenging of Cd[II] and Pb[II] ions, from aqueous solutions, by adsorption onto sawdust of Pinus sylvestris, J. Hazard. Mater. 105, 121-142.

[31] N. Eruygur, M. Atas, M. Tekin, P. Taslimi, U.M. Kocyigit and I. Gulcin (2019). In vitro antioxidant, antimicrobial, anticholinesterase and antidiabetic activities of Turkish endemic Achillea cucullata (Asteraceae) from ethanol extract, S. Afr. J. Bot. 120, 141-145.

[32] H. Teng, L. Chen, T. Fang, B. Yuan and Q. Lin (2017). Rb2 Inhibits $\alpha$-glucosidase and regulates glucose metabolism by activating AMPK pathways in HepG2 cells, J. Funct. Foods. 28, 306-313.

[33] L. Skrypnik, N. Grigorev, D. Michailov, M. Antipina, M. Danilova and A. Pungin (2019). Comparative study on radical scavenging activity and phenolic compounds content in water bark extracts of alder (Alnus glutinosa (L.) Gaertn.), oak (Quercus robur L.) and pine (Pinus sylvestris L.), Eur. J Wood Wood Prod, 77(5), 879-890.

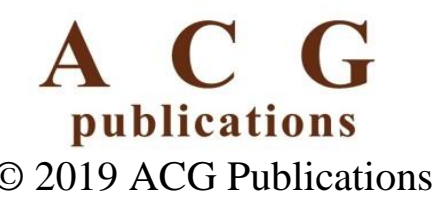

